\title{
Resting heart rate and ideal cardiovascular health: the Paris Prospective Study III
}

\author{
Hazrije Mustafic ${ }^{1 *}$, \\ Catherine Guibout ${ }^{2}$, \\ Bruno Pannier ${ }^{3}$, \\ Christof Prugger2, \\ Marie-Cécile Perier ${ }^{2}$, \\ Muriel Tafflet ${ }^{2}$, \\ Frédérique Thomas ${ }^{3}$, \\ Pierre Boutouyrie ${ }^{4}$, \\ Xavier Jouven', \\ Jean-Philippe \\ Empana $^{2}$
}

1Paris Cardiovascular Research Center (PARCC) - INSERM U970 - HEGP, Cardiovascular Epidemiology - Sudden Death Expertise Center, Paris, France

2Paris Cardiovascular Research Center (PARCC) - INSERM U970 - HEGP, Cardiovascular Epidemiology, Paris, France

${ }^{3}$ Centre dílnvestigations Preventives et Cliniques, Paris, France

${ }^{4}$ Paris Cardiovascular Research Center (PARCC) - INSERM U970 - HEGP, Pathophysiology and pharmacology of large arteries, Paris, France

\section{RECEIVED:}

September 24, 2014

\author{
KEYWORDS: resting heart rate, cardiovascular health promotion, cardiovascular prevention \\ CITATION: Cardiol Croat. 2014:9(9-10):424
}

*ADDRESS FOR CORRESPONDENCE: PARCC - INSERM U970, Team 4 "Cardiovascular Epidemiology and Sudden Death Expertise Center", 56, rue Leblanc, 75015 Paris, France. / Phone: +33629722857 /E-mail: hazrije.mustafic@inserm.fr

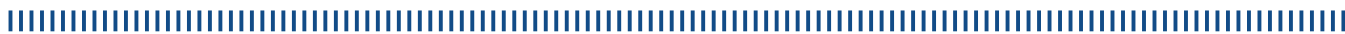

PURPOSE: Lower resting heart rate (RHR) has been related to lower risk of cardiovascular (CV) disease in large prospective studies. In 2010, the American Heart Associationës 2020 Strategic Goals defined a new concept of ideal CV health composed of 7 modifiable health metrics in order to prevent CV disease. We hypothesized that ideal CV health status would be associated with lower RHR

METHODS: We included 5166 men and women aged 50-75 years who enrolled in the Paris Prospective Study III (PPS3) from 2008 to 2011 and who were free of overt CV diseaseand treatment. The CV health status was defined as poor ( 0 or 1 health metric), intermediate (2,3 or 4) and ideal status (5, 6 or 7). RHR was measured at rest after 10 minutes in supine position and categorized in sex specific quartiles. The likelihood of alower RHR (first quartile) associated with ideal CV health status was explored by logistic regression analysis

RESULTS: Mean age was 58.9 years and 60.6\% were men. The median RHR was 61 bpm (IQR:55, 67) in men and 62 (IQR: 57 , 68 ) in women respectively. The prevalence of ideal and poor CV health status was $13.6 \%$ and $14.1 \%$ respectively. The prevalence of ideal CV status decreased while that of poor CV health status increased with RHR quartiles ( $\mathrm{P}<0.001$, Figure 1$)$. After adjusting for age and sex, participants with intermediate (OR: 1.90, 95\% CI [1.51-2.39]) and ideal CV health status (OR: 2.93 , 95\% CI [2.23-3.85]) were more likely to have a lower RHR compared with those with poor CV health status respectively.

CONCLUSION: By showing that ideal CV health status had a three-fold increased odds of having low RHR, the current data support the potential benefit that may be expected through the promotion of primordial prevention of CV disease.

DECLARATION OF INTEREST: None

\section{FIGURE 1}

Prevalence of ideal cardiovascular health status and poor cardiovascular health status among increasing resting heart rate quartiles.

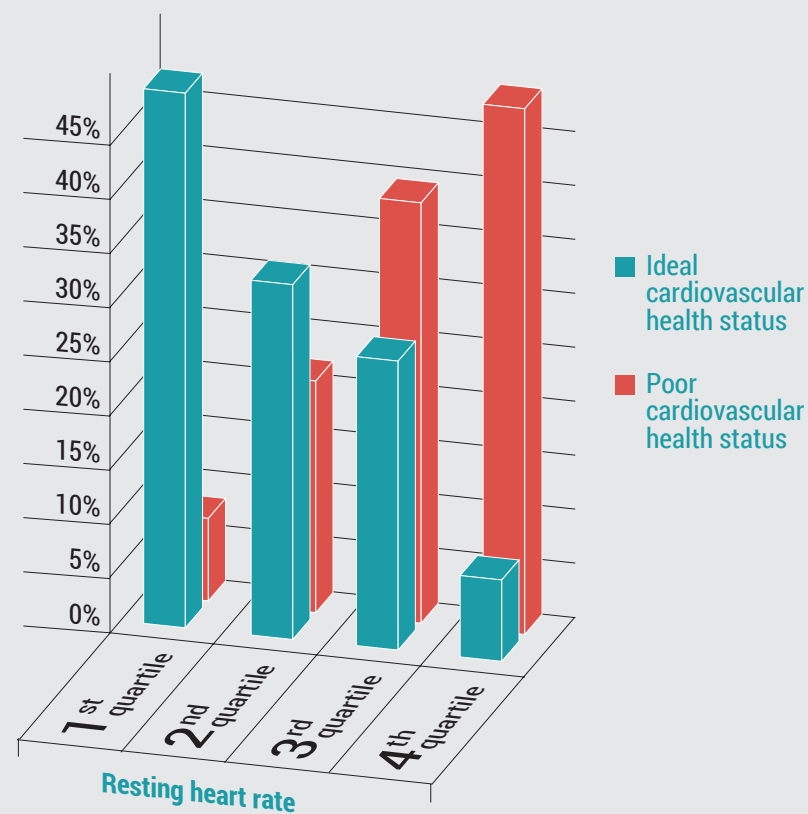

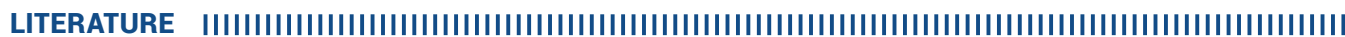

1. Jouven X, Empana JP, Escolano S, et al. Relation of heart rate at rest and long-term ( 20 years) death rate in initially healthy middle-aged men. Am J Cardiol. 2009:103(2):279-83

2. Lloyd-Jones DM, Hong Y, Labarthe D, et al; American Heart Association Strategic Planning Task Force and Statistics Committee. Defining and setting national goals for cardiovascular health promotion and disease reduction: the American Heart Association's strategic Impact Goal through 2020 and beyond. Circulation. 2010;121(4):585-613.

3. Woodward M. Webster R, Murakami Y, et al; (from the Asia Pacific Cohort Studies Collaboration). The association between resting heart rate cardiovascular disease and mortality: evidence from 112,680 men and women in 12 cohorts. Eur J Prev Cardiol. 2012;21:719-26. 